\title{
Limited knowledge and access to palliative care among women with cervical cancer: an opportunity for integrating oncology and palliative care in Zimbabwe
}

\author{
O. Tapera $^{1 *}$ (ID and A. M. Nyakabau²
}

\begin{abstract}
Background: Cervical cancer is mostly diagnosed at advanced stages among the majority of women in low-income settings, with palliative care being the only feasible form of care. This study was aimed at investigating palliative care knowledge and access among women with cervical cancer in Harare, Zimbabwe.

Methods: Sequential mixed methods design was used, consisting of two surveys and a qualitative inquiry. A census of 134 women diagnosed with cervical cancer who visited two cancer treating health facilities and one palliative care provider in Harare between January and April, 2018 were enrolled in the study. Seventy-eight health workers were also enrolled in a census in the respective facilities for a survey. Validated structured questionnaires in electronic format were used for both surveys. Descriptive statistics were generated from the surveys after conducting univariate analysis using STATA. Qualitative study used interview/discussion guides for data collection. Thematic analysis was conducted for qualitative data.

Results: Mean ages of patients and health workers in the surveys were 52 years $(S D=12)$ and 37 years ( $S D=10$,respectively. Thirty-two percent of women with cervical cancer reported knowledge of where to seek palliative care. Sixty-eight percent of women with cervical cancer had received treatment, yet only 13\% reported receiving palliative care. Few women with cervical cancer associated treatment with pain (13\%) and side effects (32\%). More women associated cervical cancer with bad smells (81\%) and death (84\%). Only one of the health workers reported referring patients for palliative care. Seventy-six percent of health workers reported that the majority of patients with cervical cancer sourced their own analgesics from private pharmacies. Qualitative findings revealed a limited or lack of cervical cancer knowledge among nurses especially in primary health care, the existence of stigma among women with cervical cancer and limited implementation of palliative policy.

Conclusions: This study revealed limited knowledge and access to palliative care in a low-income setting due to multifaceted barriers. These challenges are not unique to the developing world and they present an opportunity for lowincome countries to start considering and strategizing the integration of oncology and palliative care models in line with international recommendations.
\end{abstract}

Keywords: Cervical cancer, Access, Palliative care, Knowledge, Integration, Sequential mixed methods, Zimbabwe

\footnotetext{
* Correspondence: oscar.tapera@gmail.com

${ }^{1}$ School of Health Systems and Public Health, University of Pretoria, Pretoria,

South Africa

Full list of author information is available at the end of the article
}

(c) The Author(s). 2020 Open Access This article is distributed under the terms of the Creative Commons Attribution 4.0 International License (http://creativecommons.org/licenses/by/4.0/), which permits unrestricted use, distribution, and reproduction in any medium, provided you give appropriate credit to the original author(s) and the source, provide a link to the Creative Commons license, and indicate if changes were made. The Creative Commons Public Domain Dedication waiver (http://creativecommons.org/publicdomain/zero/1.0/) applies to the data made available in this article, unless otherwise stated. 


\section{Background}

Cervical cancer is one of the most prevalent diseases among women in the developing world, with at least $85 \%$ of the global reported cases occurring in these contexts [1]. In Zimbabwe, cervical cancer is a growing public health burden and at least 1308 new cases were reported in 2016 [2]. Unfortunately, about $80 \%$ of the cervical cancer cases present late in low-income settings when not much can be done to treat the disease. The majority of cervical cancer cases in developing countries are treated with palliative care interventions as curative modalities will not be effective due to advanced disease $[3,4]$. However; palliative care interventions in resourcelimited settings are scarce or poorly developed hence most women with cervical cancer are at risk of living and dying in severe pain and discomfort $[1,5]$.

Cervical cancer treatment and care which include modalities such as radical surgery, radiation and chemotherapy as well as palliative care are still largely centralized in Zimbabwe $[4,6]$. The costs of treatment are exorbitant and the referral systems are bureaucratic thereby limiting access to diagnosis and treatment among women with cervical cancer who need high level of care. While the government and its partners have been scaling up screening for cervical cancer using visual inspection with acetic acid cervicography (VIAC) and treatment of cervical precancers with cryotherapy and loop electrosurgical excision procedure (LEEP) across the country, diagnosis and treatment of cervical cancer is only available in two tertiary health facilities. The majority of cervical cancer cases are still presented in late stages with palliative care as the only treatment modality [4]. Demand for palliative care services among women with cervical cancer is also growing with increasing burden.

Globally there is evidence of the benefits of integrating oncology and palliative care which includes: improved survival and symptom management, reduced use of futile chemotherapy at the end of life, less patient anxiety and depression, improved patient and family satisfaction and quality of life, and efficiency in the use of healthcare resources [6]. Findings from studies from developed countries which have integrated oncology and palliative care have been mixed. However, the 2018 Lancet Commission reported that people in low and middle income settings were living and dying with little or no palliative care. The Commission gave a series of recommendations to quantify serious health-related suffering and proposed an essential package of palliative care which might also be relevant to developed countries. The use of standardized care pathways and multidisciplinary teams to promote integration of oncology and palliative care were proposed by the Commission $[6,7]$.

Zimbabwe is among the first developing countries to adopt the palliative care approach through Island
Hospice, a non-governmental organization (NGO), in 1979. Island Hospice is the centre of excellence for palliative care having trained and built capacity in many countries in Africa including Namibia, Zambia, Botswana, Kenya, and South Africa. For many years the organization attended to most oncology patients before it transitioned in 1987 to supporting patients with HIV/ AIDS and others with chronic diseases. In the 2000s Island Hospice extended the philosophy, knowledge and skills of the hospice model through capacity building of communities and health care professionals in the public health institutions to improve awareness and support the integration of palliative care into the routine health delivery system [8]. In 2014 Zimbabwe rolled out the national palliative care policy which reported that there was a huge need for palliative care interventions for people suffering from HIV and AIDS, cancer and other chronic diseases [9]. Recently, the Ministry of Health and Child Care and its partners developed a national palliative care strategy framework; however the policy is yet to be fully implemented due to limited resources and competing priorities. The country also has inadequate palliative care trained personnel in the health facilities. Since the launch of the strategic framework, 315 health workers were trained in palliative care though this is still a small number considering the growing needs. Palliative care service coverage remains limited and most health facilities experience frequent stock outs of palliative care medicines across the country. Island Hospice has been supplying the majority of opiods in public health facilities, however, access to these medicines still remains limited in the country and reliance on donor funding is unsustainable [10].

World Health Organization defined palliative care as "an approach that improves the quality of life of patients (adults and children) and their families who are facing problems associated with life-threatening illness. It prevents and relieves suffering through the early identification, correct assessment and treatment of pain and other problems, whether physical, psychosocial or spiritual" [11]. In the Zimbabwean context palliative care concept is largely relegated to terminal palliative care and a myriad of misconceptions are associated with the approach [8]. Anecdotal evidence in Zimbabwe has shown that the approach is stigmatized in communities and it is associated with death. Furthermore, the approach is still not yet fully integrated into the routine care and is still largely supported by NGOs. Understanding of palliative care and its integration into the health system remains limited in Zimbabwe despite the long history of using this approach since 1979. With the growing burden of cancers, notably cervical cancer, palliative care has become a crucial intervention for patients and families [6, 8]. Recently, the government with the support of Island 
Hospice and WHO begun the process of piloting the integration of palliative care and oncology in line with international best practices, with the hope of scaling up in future [12]. In this paper we report on our study that aimed at understanding palliative care knowledge and access among women in Zimbabwe with cervical cancer to provide evidence that could be used in programme and policy improvement.

\section{Methods}

\section{Study design}

A sequential explanatory mixed methods design was used for this study, with descriptive cross-sectional surveys being the major study and qualitative inquiry being a minor study. The purpose of the qualitative inquiry was to understand deeper issues, and to seek to explain surprising and unexpected results from the surveys. Two cross-sectional surveys namely: patient and health worker surveys were conducted on randomly selected participants in two cancer treating health facilities and one palliative care provider in Harare, Zimbabwe. The health facilities selected were Harare Central Hospital and Parirenyatwa Group of Hospital, and the palliative care provider was Island Hospice. Selection of health facilities was based on the provision of cervical cancer treatment and palliative care which is predominantly provided by Island Hospice.

\section{Target population}

The target population for the study consisted of women with cervical cancer, men, caregivers, health workers and stakeholders working in the cancer spaces in Zimbabwe. Women with cervical cancer who were at least 25 years of age were considered for enrolment in the survey. The inclusion of healthy women in qualitative inquiry was aimed at fully understanding their knowledge and perceptions about cervical cancer palliative care to inform future programmes and policies. Men and caregivers were included in the qualitative phase of the study as they play a crucial role in access of health care services [13, 14].

\section{Sample sizes and participant selection}

For the patient survey, a census of women with cervical cancer who visited the three selected health facilities was conducted between January and April 2018. A total sample of 134 women with cervical cancer was achieved. In the health worker survey a total of 78 health workers working in cervical cancer screening, treatment and palliative care sections/departments in the selected health facilities were enrolled using a census approach. The sample sizes for the qualitative data collection methods were guided by the saturation principle [15]. A total of 84 participants were selected purposively for the qualitative inquiry. The sample sizes achieved in in-depth interviews, FGDs and key informant interviews were 16, 48 and 20 respectively. The 48 participants selected for focus group discussions (FGD) were organized into 6 groups which had an average number of 8 people per group (see Fig. 1). Focus group and in-depth interview participants were selected during patient survey based on their knowledge of the disease, having good or bad experiences in seeking screening, diagnostic and treatment services and to achieve a diversity of perspectives with regards to the issues under investigation. A diverse group of young, middle aged and old patients who resided in rural and urban areas and with different disease stages were selected for both in-depth interviews and FGDs. Key informants were selected based on their experience in interacting with cervical cancer patients. These included health workers, policy makers, community leaders (pastors, prophets and traditional healers) and programme managers in NGOs providing cervical cancer services in Zimbabwe and snowball sampling technique was used to select the participants [16].

\section{Data collection}

In the two surveys, validated structured questionnaires [17] programmed in SuveytoGo software [Dooblo, Israel] in an android tablet were used to collect data from faceto-face interviews with participants [15]. Electronic data collection enabled real-time uploading of data to a cloud server and quality of control data while fieldwork was still on-going. Qualitative data collection tools which consisted of in-depth interview, key informant and FGD guides were finalized with input from survey data analysis. Qualitative data were collected using audiorecorder and notebooks. All participants consented in writing before interviews/discussions and either English or Shona language was used depending on the preference of the participant(s). Participants interviewed or enrolled for FGDs in health facilities or in communities far away from their residences were provided with an average of US\$ to cover their transport expenses.

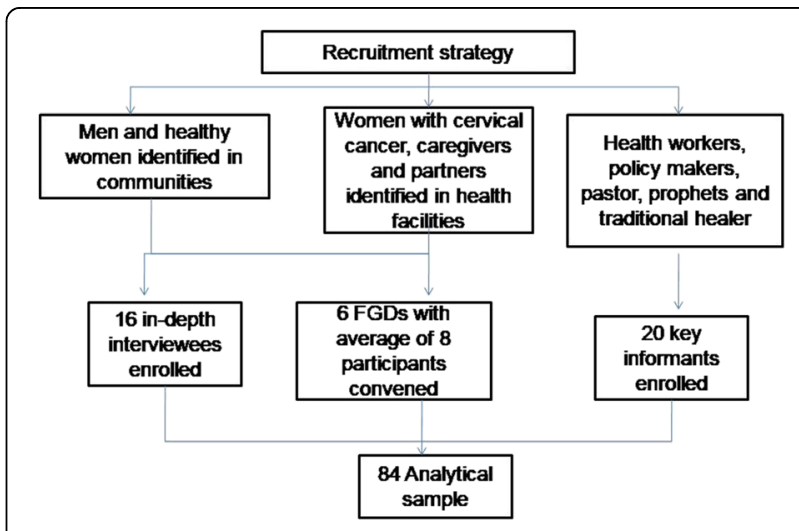

Fig. 1 Flow diagram of qualitative study recruitment 
Table 1 Socio-demographic characteristics of women with cervical cancer in Harare, Zimbabwe

\begin{tabular}{ll}
\hline Participant type & Women with cervical cancer \\
\hline Socio-demographic variables & {$[\boldsymbol{N = 1 3 4 ]}(\%)$} \\
Residence & $74(55)$ \\
Urban & $3(2)$ \\
Urban_Low density & $67(50)$ \\
Urban_High density & $4(3)$ \\
Urban_Medium density & $60(45)$ \\
Rural & Mean (52) \\
Age (years) & $6(4)$ \\
$25-34$ & $31(23)$ \\
$35-44$ & $41(31)$ \\
$45-54$ & $56(42)$ \\
55 or more & \\
Ethnicity & $130(97)$ \\
Shona & $2(1)$ \\
Ndebele & $2(2)$ \\
Other
\end{tabular}

\section{Marital status}

Married/co-habiting

Never married

1(1)

Widowed

59(44)

Divorced or separated

\section{Religion}

Roman Catholic

Protestant

24(18)

Pentecostal

34(25)

Apostolic sect

34(25)

Other

$8(7)$

\section{Education}

Primary

Secondary

Higher

None

$10(7)$

Household head education

Primary

Secondary

$50(37)$

Higher

14(10)

Not Applicable

5(4)

None

49(37)

\section{Occupation}

Unemployed

90(67)

Student

Professional

$3(2)$

Police/Military/Security
Table 1 Socio-demographic characteristics of women with cervical cancer in Harare, Zimbabwe (Continued)

\begin{tabular}{ll}
\hline Participant type & Women with cervical cancer \\
\hline Trucker/transport business & $1(1)$ \\
General worker & $1(1)$ \\
Self employed & $5(4)$ \\
Vendor & $16(12)$
\end{tabular}

Occupation of household head

$\begin{array}{ll}\text { Unemployed } & 25(19) \\ \text { Farm worker } & 2(1) \\ \text { Professional } & 23(17) \\ \text { Police/Military/Security } & 5(4) \\ \text { Trucker/transport business } & 1(1) \\ \text { General worker } & 0 \\ \text { Self employed } & 30(22) \\ \text { Vendor } & 1(1) \\ \text { Other } & 47(35)\end{array}$

Personal income (US\$)

$\begin{array}{ll}\text { No income } & 77(57) \\ <200 & 32(24) \\ 200-400 & 19(14) \\ 430 \text { or more } & 6(4)\end{array}$

Household income (US\$)

No income $71(53)$

$<600 \quad 53(40)$

600-1000 6(4)

1200 or more 4(3)

Medical insurance/aid

Yes 27(20)

No 107(80)

Wealth quintiles

Poorest 7(5)

Poorer 32(24)

Middle 36(27)

Richer 26(19)

Richest 33(25)

Sources of cervical cancer information

$\begin{array}{ll}\text { Radio } & 31(25) \\ \text { TV } & 27(21) \\ \text { Health workers } & 57(45) \\ \text { Other } & 11(9)\end{array}$

Knowledge that cervical cancer is treatable

Yes

$113(84)$

No

$7(5)$

Don't

$14(11)$ 
Table 1 Socio-demographic characteristics of women with cervical cancer in Harare, Zimbabwe (Continued)

\begin{tabular}{ll}
\hline Participant type & Women with cervical cancer \\
\hline $\begin{array}{l}\text { Cervical cancer disease stages } \\
\leq 2 \mathrm{~b} 1\end{array}$ & $6(4)$ \\
$2 \mathrm{~b} 11-4$ & $128(96)$ \\
Cervical Cancer treatment status & \\
$\quad$ Yes & $92(69)$ \\
No & $42(31)$ \\
Received palliative care & \\
Yes & $17(13)$ \\
No & $117(87)$ \\
\hline
\end{tabular}

\section{Data analysis}

Data from the surveys was downloaded from a cloud server in Excel format which was then imported into STATA. After data cleaning, univariate analyses were conducted to yield descriptive statistics, using as outcome variables cervical cancer palliative care knowledge and access to palliative care among women with the disease. All survey analyses were conducted independently using STATA version 14 software (StataCorp, Texas). For the qualitative inquiry, all recordings were transcribed and translated into English verbatim. The transcripts were loaded into Dedoose software where line-by-line coding was conducted using a thematic coding framework that had been developed from literature and survey findings. After coding, analysis was conducted using the same software to identify the salient emerging themes relevant to this study from the data. The main themes were reported and supported by direct quotes from some of the participants.

\section{Results}

\section{Quantitative results}

\section{Characteristics of participants}

A total of 212 participants responded to the two surveys, 134 women with cervical cancer and 78 health workers. The mean ages of participants in the patient and health worker surveys were 52 years $(\mathrm{SD}=12)$ and 37 years $(\mathrm{SD}=10)$, respectively. Table 1 shows the characteristics of women with cervical cancer: $94 \%$ had advanced disease (FIGO stage $\geq 2 \mathrm{~b} 2$ ), $61 \%$ had at least secondary education, $53 \%$ had no income, $67 \%$ were unemployed, $56 \%$ were poor or in middle class and $60 \%$ were widowed, divorced or separated. Sixty-nine percent (69\%) of women with cervical cancer had received treatment yet only $13 \%$ reported receiving palliative care.

Table 2 shows low knowledge (32\%) of where to seek for palliative care services. Fewer women with cervical cancer associated treatment with pain (13\%) and side effects (32\%). However, more women associated cervical cancer with bad smells (81\%) and death (84\%).
Table 2 Knowledge and perceptions of cervical cancer and palliative care among women with cervical cancer in Harare, Zimbabwe

\begin{tabular}{|c|c|}
\hline Variable & $\begin{array}{l}\text { Women with cervical cancer } \\
\text { participants }[N=134](\%)\end{array}$ \\
\hline $\begin{array}{l}\text { Knowledge of where to seek } \\
\text { for palliative care services }\end{array}$ & $43(32)$ \\
\hline $\begin{array}{l}\text { Local health facilities offer counseling } \\
\text { to cervical patients and their families }\end{array}$ & $111(83)$ \\
\hline $\begin{array}{l}\text { Local health facility offers health } \\
\text { education about cervical cancer } \\
\text { to women. }\end{array}$ & $92(69)$ \\
\hline Cervical cancer treatment is painful & $18(13)$ \\
\hline Cervical cancer treatment has side effects & $43(32)$ \\
\hline Cervical cancer is painful & $33(25)$ \\
\hline Cervical cancer is smelly & $109(81)$ \\
\hline Cervical cancer can cause death & $113(84)$ \\
\hline
\end{tabular}

Table 3 shows that a high proportion (72\%) of health workers had received adequate training to provide treatment and palliative care of cervical cancer patients. Seventy-six (76\%) of health workers reported having guidelines for the treatment and palliation of cervical cancer patients in their health facilities. Most health workers (96\%) reported that the majority of women with cancer of cervix presented late. Only one health worker referred patients for palliative care at Island Hospice or other service providers or to a palliative care specialist three months prior to the survey. Less than half of health workers reported that most patients with cervical cancer were accessing treatment and palliative care and this was based on their professional experiences with cervical cancer patients/survivors. Stock-outs of analgesics across the three-step ladder three months prior to the surveys

Table 3 Knowledge and perceptions of palliative care among health workers

\begin{tabular}{ll}
\hline Variable & $\begin{array}{l}\text { Health worker } \\
\text { participants [N = 78] (\%) }\end{array}$ \\
\hline $\begin{array}{l}\text { Adequacy of training to provide cervical } \\
\text { cancer treatment and palliative care }\end{array}$ & $56(72)$ \\
$\begin{array}{l}\text { Availability of clinical guidelines for cervical } \\
\text { cancer treatment and palliative care. }\end{array}$ & $59(76)$ \\
$\begin{array}{l}\text { Most women present late with cervical } \\
\text { cancer }\end{array}$ & $75(96)$ \\
Referral for palliative care & $1(1)$ \\
$\begin{array}{l}\text { Most women having access to treatment } \\
\text { and palliative care for cervical cancer }\end{array}$ & $37(47)$ \\
$\begin{array}{l}\text { Stock-outs of analgesics in previous 3 months } \\
\text { Adequacy of analgesics for palliative care }\end{array}$ & $39(50)$ \\
$\begin{array}{l}\text { Patients buy their own analgesics for palliative } \\
\text { care }\end{array}$ & $59(76)$ \\
\hline
\end{tabular}


were reported by $22 \%$ of the health workers. Half of the health workers perceived that their facilities had adequate analgesics for palliative care of patients with cervical cancer. A large proportion of health workers (76\%) reported that the majority of patients were responsible for purchasing their own analgesics for palliative care.

\section{Qualitative results}

Main theme: palliative care knowledge and access is limited The salient main theme from the qualitative inquiry was that among patients and health workers alike palliative care knowledge is still limited in Zimbabwe. Palliative care access or perceptions of it were reported as limited even among women who had access to other treatment modalities.

\section{Subtheme: poor understanding of palliative care}

One of the major subtheme emerging from this study was that there is a general perception that palliative care is end-of-life care and should only be given when all other interventions have failed and the patient is about to die.

One FGD healthy woman participant from Hopely community described palliative care as follows:

"If the doctors tell you that the condition can no longer be treated we should be able to comfort our patient and to have a peace of mind. The hospital staff told us that there was no help they could offer to our patient unless if we had come earlier and she was given pain killers though she could not survive for long. Generally, advanced cervical cancer is seen as a death sentence in our communities"

"You walk into a rural health facility and you ask nurses about cervical cancer or cancer in general but they have no clue of what it is but we are asking people in the community to go to the clinic where the nurses don't know anything about cancer."-Cancer Programme Manager

One pharmacologist reported the need for strengthening health education:

"I think people need to be educated, and we need to inform people why it helps, and how long they will survive getting this help. Some would have seen people with cervical cancer suffering and they would just think they are dying".

\section{Subtheme: stigmatization of cervical cancer and palliative care}

Some participants reported that cervical cancer and palliative care were associated with stigma and people linked them with the nearing of death. One informant said:

"I remember one of my patients who was being seen by Island Hospice and they used to have cars with the Island Hospice logo and I mean if you are staying in high density areas you are like identified like, ooh those ones that see that woman who is dying from cervical cancer and so the patient associated attending palliative care services as something that is associated with dying such that they would rather shun those services because then by accepting services from them means they are accepting that they are dying and that's one of the problems that palliative care services have".

Another health professional informant also described advanced cervical cancer and palliative care as associated with stigma.

"Maybe they stigmatize the disease [cervical cancer] and palliative care approach because nothing else can be done, which is true because when you offering palliative care you are just offering symptomatic care either pain relief or wound care. So I think communities need better understanding of the disease [cervical cancer] itself and to know that nothing may be done to cure advanced disease and all that needs to be done is just to let that person live a more comfortable life until the end"- Senior Gynaecologist

\section{Subtheme: palliative care is relegated to hospices or nursing homes by health workers}

There is a general perception among some health workers that palliative care is only provided by hospices and is the last level of care for advanced disease. This perception has also permeated to the patients who believe that when doctors can longer do anything that is when they need palliative care.

"Yes, but when it comes to cancer the Island Hospice, the Cancer Centre are the two names linked to palliative care and patients would want to know if the doctors have got nothing to do for them and theirs is a hopeless situation". - Senior Radiographer

Subtheme: pain management is compromised by high costs of medicines

High costs of medicines for cancer patients are a barrier to accessing pain management which is a key component of palliative care. While some organizations like Island Hospice provide it for free, because of the high 
costs of treatment of cancer some patients just give up seeking or pursuing health services.

".....for some time there has been a cost attached to it and that cost has been a deterrent". - WHO expert

"...... if you are suspected of cervical cancer the next stages needed for confirmation are very expensive...."- Hopely FGD participant, healthy woman.

".....in Zimbabwe drugs aren't available if they are there they are expensive and that's another barrier to access."- Pharmacologist

\section{Subtheme: limited implementation of palliative care policy framework}

One of the emerging subthemes from key informants was that the existing palliative care strategy framework was not fully implemented in the country due to limited resources. Some key informants had the following to say:

"In terms of palliative care when we think of palliative care specialists it's not really incorporated... I don't know at what stage the patient has to get to be before a palliative care specialist but I don't think this is happening there."- Pharmacologist "........so that's why I am saying we don't have that system of palliative care on the government side."Senior Gynaecologist

".....health system here we don't even believe that it can handle the number of clients that this country has, you know how many centres we have, how many oncologists do we have and so forth"- WHO expert "........we need to have guidelines that are set up by a multi-disciplinary team. It must be the whole team. It must be pathologists, it must be oncologists, it must be gynaecologists, it must be the nurses, epidemiologists coming together looking at the data, looking at the population coming up with guidelines that work for us here in Zimbabwe. At the moment there are no guidelines everybody is just doing what they think. You know we have MSF they are doing their own project, Family health care their own...."- Senior Pathologist

\section{Discussion}

This study revealed a number of issues with regards to palliative care for cervical cancer. There is limited knowledge of palliative care approach based on the low proportions of women with cervical cancer who knew where to go to seek for palliative care. Few women associated cervical cancer treatment as causing with pain and side effects. The majority of women with cervical cancer reported the availability of counseling services and health education for cervical cancer in their local health facilities. The majority of women associated cervical cancer with pain, bad smells and death. A high proportion (69\%) had received treatment, however only $13 \%$ reported receiving palliative care. Most health workers reported having knowledge about guidelines for treatment and palliation of cervical cancer patients and receiving adequate training for their roles in treatment and palliation of cancer patients. However, only one health worker reported referring cervical cancer patients for palliative care services at Island Hospice or other providers. Most cervical cancer patients sourced their own analgesics from private pharmacies. Qualitative findings revealed: limited or lack of cervical cancer knowledge among nurses especially in primary health care, the existence of stigma among women with cervical cancer and limited implementation of palliative strategy framework.

The findings of this study showed limited knowledge or poor understanding about palliative care for women with advanced cervical cancer. The Lancet Commission recently reported that public awareness of palliative care and associated services were scarce even in developed countries [6]. In a UK study, only $19 \%$ of patients recognized the term palliative care while $68 \%$ understood the role of hospices and $67 \%$ understood the roles of specialist palliative care nurses [18]. Hirai and colleagues [19] reported in their study that $63.1 \%$ of respondents had no knowledge of palliative care and as little as $0.5 \%$ were using palliative care services in Japan. These findings are consistent with those from our study. Our qualitative work revealed that poor understanding of palliative care could be driven by stigma associated with advanced cervical cancer, palliative care and the fact that it affects the cervix, a private part of the body of a woman [6]. Other studies have also supported this finding that stigma surrounding cancer presented barriers to treatment and care. The social, emotional and financial devastation that accompanies the diagnosis of cancer is driven by cultural myths and taboos surrounding the disease [6, 20-22].

Low perceptions of pain and side effects associated with cervical cancer treatment could be explained by the fact that most women have the perception that cervical cancer is painful. Therefore, any pain or side effect experienced during or after treatment is negligible or is attributed to the disease and not to the treatment modalities themselves. Furthermore, survival outcomes for women treated in developing countries are low [1, 20] hence there may not be much knowledge of long term side effects. This is supported by the general perception from our qualitative inquiry that advanced cervical cancer is a "death sentence" hence if one has the disease they will not live long. Awareness and health education in the communities including among women with cervical cancer and health workers require further 
strengthening to improve knowledge about palliative care approach.

Limited counseling and health education services in local health facilities were reported in this study. Qualitative data also supported this finding which revealed limited or lack of knowledge about cervical cancer among nurses particularly in rural areas. This further suggests limited policy framework implementation and absence of priorities for palliative care from the government of Zimbabwe. There is a common misconception that palliative care is end-of life care only and coupled with stigmatization of death and dying most people have not embraced the contemporary concept of palliative care which starts at diagnosis. This has resulted in people resorting to "palliative care" interventions as the last resort and this is also common even among health workers [6]. Studies in developed settings have also reported that patients with advanced diseases were referred to hospices or nursing homes when they could not stay in their homes. However, other studies have shown that the quality of life of patients who are kept in hospices or nursing homes is lower than those who stay with their families at home [6, 21-23]. While the government of Zimbabwe has rolled out the palliative strategy framework, more resources and priorization are required to fully implement the policy.

Access to palliative care was limited even among patients who had received some other forms of treatment in this study. Only one health worker reported referring cervical cancer patient for palliative care. Greer and colleagues in their USA study reported that late referral to hospices deprives the entire family from comprehensive support care they could beneficial from [24]. Qualitative findings supported the results from the surveys, suggesting that patients were referred only when all other interventions had "failed" or as the last resort or when the patient is nearing death. There are also no clear guidelines about the pathways of care in health facilities across the country. While a high proportion of health workers reported availability of clinical guidelines for the treatment of cervical cancer including palliative care, qualitative data revealed that the guidelines were not updated, standardized and fully implemented in treating health facilities. This status quo suggests limited implementation of the national palliative care policy on the backdrop of limited resources and competing priorities in the health sector [10]. High costs of medicines and other treatment procedures were reported as barriers to accessing pain management in our context. These barriers were also reported in the Lancet Commission [6] and other studies [25-27]. There are opportunities for Zimbabwe to engage the private sector, local and international partners to support the full integration of palliative care into the health system for optimal outcomes.

\section{Limitations and strength of the study}

The main limitations of this study were: findings from cross sectional surveys may not be used to infer causality and results from qualitative inquiries may not be generalizable beyond the study settings. However, the study had its own strength; the use of both quantitative and qualitative methods provided better research outcomes for policy recommendations.

\section{Conclusion}

In conclusion, our study revealed limitations in knowledge and access to palliative care due to a myriad of multi-faceted barriers in a low-income context. Furthermore, these challenges are not unique to the developing world and they present an opportunity for low-income countries to start considering and strategizing the integration of oncology and palliative care models in line with international recommendations. Low-income countries could rally behind developed countries that are in advanced stages of integration using different models informed by evidence and their contextual circumstances. Sound policies, strong political will and significant investments underpin the success of any integration model, thus collaborations with industry, academic institutions and international organizations are recommended.

\section{Abbreviations \\ FGD: Focus Group Discussion; VIAC: Visual inspection with acetic acid cervicography; WHO : World Health Organization}

\section{Acknowledgements}

We are grateful to the women and patients who participated in our study. Special appreciation also goes to our research assistants who assisted in data collection and analysis for this study.

\section{Authors' contributions}

OT: researcher, concept and study design; AMN: concept and study design, clinical oversight, critical revision and editing. All authors reviewed and approved this manuscript.

\section{Funding}

This study was funded by the Letten Foundation, Norway. The funding organization did not participate in the design, data collection, analysis, interpretation and development of this manuscript. The views expressed in this manuscript are solely those of the authors and not the funding organization.

\section{Availability of data and materials}

The datasets used and/or analyzed during the current study are available from the corresponding author on reasonable request.

\section{Ethics approval and consent to participate}

This study was approved by several ethics committees/bodies:

1. University of Pretoria, Faculty of Health Sciences Research Ethics Committee (REC 487/17).

2. Harare Hospital Ethics Committee (HCHEC 271017/77)

3. Joint Parirenyatwa and University of Zimbabwe Research Ethics committee (JREC 33A/18).

4. Medical Research Council of Zimbabwe (MRCZ/A/ 2271).

All participants in this study were consented in writing before interviews.

Consent forms were administered by the researchers in the language of the participant's preference i.e. English or Shona (local language spoken by majority of people in Zimbabwe). 


\section{Consent for publication}

Not applicable.

\section{Competing interests}

The authors declare no conflict of interests.

\section{Author details}

${ }^{1}$ School of Health Systems and Public Health, University of Pretoria, Pretoria, South Africa. ${ }^{2}$ Parirenyatwa Group of Hospitals, Radiotherapy Centre, Harare, Zimbabwe.

Received: 2 May 2019 Accepted: 5 February 2020

Published online: 13 February 2020

\section{References}

1. Wu ES, Jeronimo J, Feldman S. Barriers and challenges to treatment alternatives for early-stage cervical cancer in lower-resource settings. Journal of Global Oncology. 2017;3(5):572-82.

2. E Chokunonga, MZ Borok, T Chingonzoh, ZM Chirenje, R Maakunike-Mutasa, P Manangira et al.: Patterns of Cancer in Zimbabwe in 2016, Zimbabwe National Cancer Registry, 2018.

3. Chirenje ZM, Rusakaniko S, Kirumbi L, Ngwalle EW, Makuta-Tlebere P, Kaggwa $S$, et al. Situation analysis for cervical cancer diagnosis and treatment in east, central and southern African countries. Bull World Health Organ. 2001;79:127-32.

4. Nyakabau AM. Priorities for cancer prevention and control in Zimbabwe. Cancer Control. 2014:126-30.

5. Grant L, Brown J, Leng M, Bettega N, Murray SA. Palliative care making a difference in rural Uganda, Kenya and Malawi: three rapid evaluation field studies. BMC palliative care. 2011;10(1):8.

6. Kaasa S, Loge JH, Aapro M, Albreht T, Anderson R, Bruera E, et al. Integration of oncology and palliative care: a lancet oncology commission. The Lancet Oncology. 2018.

7. Knaul FM, Farmer PE, Krakauer EL, De Lima L, Bhadelia A, Kwete XJ, et al. Alleviating the access abyss in palliative care and pain relief-an imperative of universal health coverage: the lancet commission report. Lancet. 2018; 391(10128):1391-454.

8. Khumalo T, Maasdorp V. The Island Hospice model of palliative care. ecancermedicalscience. 2016;10.

9. "Palliative care gains ground in Zimbabwe" [http://newsofthesouth.com/ palliative-care-gains-ground-in-zimbabwe/] [Accessed on 20 January,2020].

10. "Commemorating the World Hospice and Palliative care day". [http://www. mohcc.gov.zw/index.php?option=com_content\&view=article\&id=262: commemoration-of-world-hospice-and-palliative-care-day\&catid=84 \&ltemid=435] (Accessed on 18 January,2020).

11. https://www.who.int/news-room/facts-in-pictures/detail/palliative-care [Accessed on 18 January,2020).

12. "Govt works on integrating palliative care" [https://www.herald.co.zw/govtworks-on-integrating-palliative-care/] [ Accessed on 22 January,2020).

13. Grande G, Stajduhar K, Aoun S, Toye C, Funk L, Addington-Hall J, et al, Supporting lay carers in end of life care: current gaps and future priorities. Palliat Med. 2009;23(4):339-44.

14. Kangethe $\mathrm{S}$. The perfidious experiences of men as palliative caregivers of people living with HIV/AIDS and other terminal illnesses in Botswana. Eclectic data sources. Indian journal of palliative care. 2010;16(3):174.

15. Creswell JW. Research design: qualitative, quantitative, and mixed methods approaches (4th ed). Thousand Oaks, CA: Sage; 2013.

16. Kumar K. Conducting key informant interviews in developing countries. Washington,DC: Agency for International Development (AID); 1989. Report No.: 13.

17. Tapera O, Dreyer G, Stray-Pedersen B, Hendricks SJH. Design and validation of questionnaires investigating access and utilization of cervical cancer treatment and palliative care. Global J Health Sci. 2018;11(1):113. https://doi. org/10.5539/gjhs.v11n1p113.

18. Koffman J, Burke G, Dias A, Raval B, Byrne J, Gonzales J, et al. Demographic factors and awareness of palliative care and related services. Palliat Med. 2007;21(2):145-53.

19. Hirai K, Kudo T, Akiyama M, Matoba M, Shiozaki M, Yamaki T et al. Public Awareness, Knowledge of Availability, and Readiness for Cancer Palliative Care Services: A Population-Based Survey across Four Regions in Japan. Journal of Palliative Medicine. 201; 14 (8): 918-922.
20. Kuguyo O, Matimba A, Tsikai N, Magwali T, Madziyire M, Gidiri M, et al. Cervical cancer in Zimbabwe: A situation analysis. Pan Afr Med J. 2017;27: 215. doi:https://doi.org/10.11604/pamj.2017.27.215.12994.

21. Tang P-L, Mayer DK, Chou F-H, Hsiao K-Y. The experience of cancer stigma in Taiwan: a qualitative study of female cancer patients. Arch Psychiatr Nurs. 2016;30(2):204-9.

22. Suwankhong D, Liamputtong P. Breast cancer treatment: experiences of changes and social stigma among Thai women in southern Thailand. Cancer Nurs. 2016;39(3):213-20.

23. Cherny NI. Stigma associated with "palliative care" getting around it or getting over it. Cancer. 2009;115(9):1808-12.

24. Greer JA, Jackson VA, Meier DE, Temel JS. Early integration of palliative care services with standard oncology care for patients with advanced cancer. CA Cancer J Clin. 2013;63(5):349-63.

25. Beccaro M, Costantini M, Merlo DF. Inequity in the provision of and access to palliative care for cancer patients. Results from the Italian survey of the dying of cancer (ISDOC). BMC public health. 2007;7(1):66.

26. Kumar P, Casarett D, Corcoran A, Desai K, Li Q, Chen J, et al. Utilization of supportive and palliative care services among oncology outpatients at one academic cancer center: determinants of use and barriers to access. J Palliat Med. 2012;15(8):923-30.

27. Kwon JH. Overcoming barriers in cancer pain management. J Clin Oncol. 2014;32(16):1727-33

\section{Publisher's Note}

Springer Nature remains neutral with regard to jurisdictional claims in published maps and institutional affiliations.
Ready to submit your research? Choose BMC and benefit from:

- fast, convenient online submission

- thorough peer review by experienced researchers in your field

- rapid publication on acceptance

- support for research data, including large and complex data types

- gold Open Access which fosters wider collaboration and increased citations

- maximum visibility for your research: over $100 \mathrm{M}$ website views per year

At BMC, research is always in progress.

Learn more biomedcentral.com/submissions 